\title{
The spacing effect in 4- to 9-year-old children
}

\author{
CORNELIUS P. REA and VITO MODIGLIANI \\ Simon Fraser University, Burnaby, British Columbia, Canada
}

\begin{abstract}
Experiment 1 of the current research failed to replicate Toppino and DiGeorge's (1984) finding that older children but not preschoolers showed a spacing effect. Instead, we obtained the spacing effect in all the age groups tested (preschool, kindergarten, first-grade, and third-grade children). The effect was demonstrated with two types of material, words and pictures. Experiment 2 focused on the role that very brief spacings, with no intervening items between repetitions, play in later retention. Age groups and materials were the same as in Experiment 1. Four different levels of spacing were included (0-, 1.1-, 2.5-, and 5-sec intervals). The spacing effect was again obtained for all age groups with both words and pictures. The results of both experiments suggest that the spacing effect does not emerge with development.
\end{abstract}

Since Melton's $(1967,1970)$ seminal papers, the spacing effect has received a great deal of attention (for reviews, see Crowder, 1976; Hintzman, 1974, 1976). The spacing effect refers to the fact that as spacing between repeated items increases, subsequent recall also improves. Empirically, it is a robust phenomenon, having been demonstrated with a variety of paradigms and materials (e.g., Bloom \& Shuell, 1981; Kintsch, 1966; Landauer \& Ross, 1977; Schwartz, 1975; Shaughnessy, 1977; Whitten \& Bjork, 1977). Theoretically, however, the spacing effect has posed significant difficulties of interpretation. Although many formulations have been advanced, no single generally accepted explanation of the spacing effect has yet emerged.

The major problem with testing any theory of the spacing effect is that the basic experimental manipulation (i.e., variation of the interval between repeated presentations) can be conceptually correlated with many different processes. As will be discussed later, theories have appealed to such different processes as rehearsal, encoding variability, consolidation, habituation, and effort, and any one of these, or a combination of them, could be responsible for the effect. In addition, control processes used by adult subjects may mask the operation of more fundamental mechanisms and thus render their discovery more difficult. One way of reducing the number of possibilities is to use relatively naive subjects, such as young children, who do not engage in the kind of control processes that are common with more sophisticated subjects (e.g., Flavell, Beach, \& Chinsky, 1966; Ornstein \& Naus, 1978).

We gratefully acknowledge the help of H. G. Gabert, Kitty Gustafson, Teresa MacInnes, and Wayne Tressel. We also express our gratitude to the principals, teachers, and children of Highlands Preschool, North Vancouver, B.C.; Kerrisdale Elementary School, Vancouver, B.C. Lochdale Community School, Burnaby, B.C.; and Simon Fraser University Daycare Centre, Burnaby, B.C.

Requests for reprints should be sent to Vito Modigliani, Department of Psychology, Simon Fraser University, Burnaby, British Columbia V5A 1S6, Canada.
Surprisingly, only four studies have adopted a developmental perspective in investigations of the spacing effect (i.e., Cornell, 1980; Toppino \& DeMesquita, 1984; Toppino \& DiGeorge, 1984; Wilson, 1976). Most intriguing are the results reported by Toppino and DiGeorge, who, as far as we are aware, carried out the only developmental study that tested preschoolers. Using the free-recall paradigm and pictures of common objects, Toppino and DiGeorge found the spacing effect with first-grade children (mean age $=6.7$ years) but not with preschoolers (mean age $=4.3$ years). Toppino and DiGeorge concluded that the spacing effect in free recall may depend on the development of certain cognitive mechanisms. If they are correct, the incorporation of cognitive processes that emerge with development, such as attentional or rehearsal strategies under voluntary control, apparently are necessary to account for the spacing effect. In other words, support for Toppino and DiGeorge's position tends to eliminate any theory of the spacing effect that assumes the operation of more fundamental or primitive mechanisms, which operate automatically. A confirmation of the developmental trend obtained by Toppino and DiGeorge, therefore, seemed important. Experiment 1 of the present study sought to replicate Toppino and DiGeorge's findings, but the results did not support their claim that the spacing effect emerges with development. Instead, the spacing effect was demonstrated at all developmental levels tested (i.e., preschool to third grade). Experiment 2 tested the hypothesis that, with young children, increasing the length of blank intervals between presentations is sufficient to produce the spacing effect.

\section{EXPERIMENT 1}

Experiment 1 primarily attempted to verify Toppino and DiGeorge's (1984) conclusion that the spacing effect emerges with development. A number of modifications were implemented in order to eliminate some methodological problems that may have been present in their study. 
Toppino and DiGeorge used manual presentation of pictures at a 5-sec rate. This procedure has little to recommend it. Timing accuracy is a crucial variable in the presentation of visual material, and any variation can have a dramatic effect on subsequent performance. Loftus and Kallman (1979) reported that very brief variations in exposure time can have substantial effects on recognition memory. Furthermore, Loftus (1982) pointed out not only that precise control over exposure time is critical, but also that "hand presentations should be used only as a last resort" (p. 265).

More precise control over presentation of stimulus material was required. Thus, instead of manual presentation, a rearview screen projector with both audio and visual modes of presentation was used. Presentation duration of the items was precisely timed by electronic cue pulses on an audio tape that controlled both auditory and visual presentation.

A further factor that could have a bearing on Toppino and DiGeorge's (1984) conclusions was their use of pictures (rather than verbal material). Although pictures have been used in other studies (e.g., Hintzman \& Rogers, 1973), they are not the usual type of material used in investigations of the spacing effect. Inclusion of word lists in addition to pictures would avoid any confounding attributable to possible differential processing of pictures by older and younger children. Thus, word lists, in addition to picture lists, were included in the present study.

Toppino and DiGeorge (1984) compared three conditions in their study, a once-presented item (1P) and two levels of spacing, Lag 0 and Lag 3. It would be of some interest to determine the effect of some intermediate level of spacing, such as Lag 1. In Experiment 1, in addition to the 1P items, three levels of spacing were compared: Lag 0, Lag 1, and Lag 3.

A wider age range was also used. In addition to the two age groups Toppino and DiGeorge (1984) used (i.e., preschool and first grade), two additional groups (i.e., kindergarten and third-grade children) were included in the present study to map more precisely the developmental course of the spacing effect.

\section{Method}

Subjects. The subjects were 96 children, 24 each from four age groups: preschool (mean age $=4.0$ years), kindergarten (mean age $=5.4$ years), first grade (mean age $=6.5$ years) and third grade (mean age $=8.3$ years). Approximately half the children were male and half were female, and all were from a local preschool and elementary school.

Design. The design was a $4 \times 2 \times 4$ factorial involving the comparison of the four age groups just described, two types of material (words and pictures), and four different levels of spacing (1P and 0,1 , and 3 intervening items). Age was a between-subjects variable, and material and spacing were within-subject variables. A 2-min oral free-recall test was given immediately after presentation of the last item in each list.

Materials and Apparatus. As noted above, Toppino and DiGeorge (1984) used only pictures, and their findings may have been a function of this type of material. In the present research, words were included to address the issue of generality across stimu- lus materials. The words were one- or two-syllable concrete nouns taken from Wepman and Hass's (1969) spoken word count for children 5-7 years of age. The words were typed in an uppercase block typeface (Helvetica) on a white background. They were photographed with a close-up lens and developed as $35 \mathrm{~mm}$ slides. Pictures, corresponding to the words, were black line drawings on a white background (after Snodgrass \& Vanderwart, 1980) and were similarly made into slides.

The slides were presented audiovisually to the subjects on a Bell \& Howell Model 797 rearview screen projector. Slide presentation was controlled by an electronic cue pulse on one track of an audiocassette tape. Slides were changed at a 5-sec rate, and slide onset was accompanied by an audio presentation of the item (female voice) recorded on the other track of the tape. (Note that the audio component was necessary with the younger children during word-list presentation because these subjects were unable to read.) Blank time between slides was $1.1 \mathrm{sec}$. The screen was $24 \times 24 \mathrm{~cm}$, and the height of the letters in the words was $2.5 \mathrm{~cm}$. The pictures were proportioned according to guidelines recommended by Snodgrass and Vanderwart (1980) and varied in size from approximately $13 \times 9 \mathrm{~cm}$ to $18 \times 14 \mathrm{~cm}$.

For each type of stimulus material (words and pictures) 16 lists were constructed. Each list consisted of 16 positions. The first 2 and last 3 positions were reserved for primacy and recency buffers, respectively. The middle portion of each list consisted of 11 positions. Six of these were taken by three items presented twice; one item had Lag 0 (there were no intervening items between presentations), one had Lag 1 (one intervening item), and one had Lag 3 (three intervening items). One position was taken by a $1 \mathrm{P}$ item. The remaining four positions were occupied by filler items. To ensure that any given item would serve in all four presentation conditions (i.e., 1P and Lags 0,1 , and 3 ) and that each item was equally represented in all positions in the lists, a Greco-Latin square principle was used to counterbalance both items and conditions. Thus, over subjects and lists, there was no confounding of lag with serial position. Each subject received 2 word lists (W) and 2 picture lists (P). For counterbalancing purposes, eight separate sequences, each consisting of 2 word lists and 2 picture lists, were constructed. In every group, 3 subjects each received one of the eight sequences. Half the subjects received a W, P, W, P order, and half received a $\mathbf{P}, \mathbf{W}, \mathbf{P}, \mathbf{W}$ order.

Procedure. The subjects were tested individually. Each child was presented with a sequence containing two lists of words and two lists of pictures. Each subject listened to a standard set of instructions. A brief practice session followed. When it was clear that the child understood the task, the experimental lists were presented. As each word or picture was presented audiovisually, the subject was required to verbalize that item aloud. Immediately following the presentation of each list, a 2-min oral free recall was given, and responses were tape-recorded for later analysis. If a child stopped responding during the recall period before the $2 \mathrm{~min}$ had elapsed, two prompts were used. The first of these was "Try really hard and see if you can think of any more words/pictures," and the second was "You still have some time left, can you think of any more words/pictures?" If the child could not remember any other items shortly after the second prompt, the next list was presented.

\section{Results}

On the basis of whether he/she recalled neither, one, or both critical items in each of the four spacing conditions (1P and Lags 0, 1, and 3), each subject obtained a score of 0,1 , or 2 for each type of material (words and pictures). The results are summarized in Figure 1.

The following analyses are reported with respect to specific questions. The level of statistical significance is 


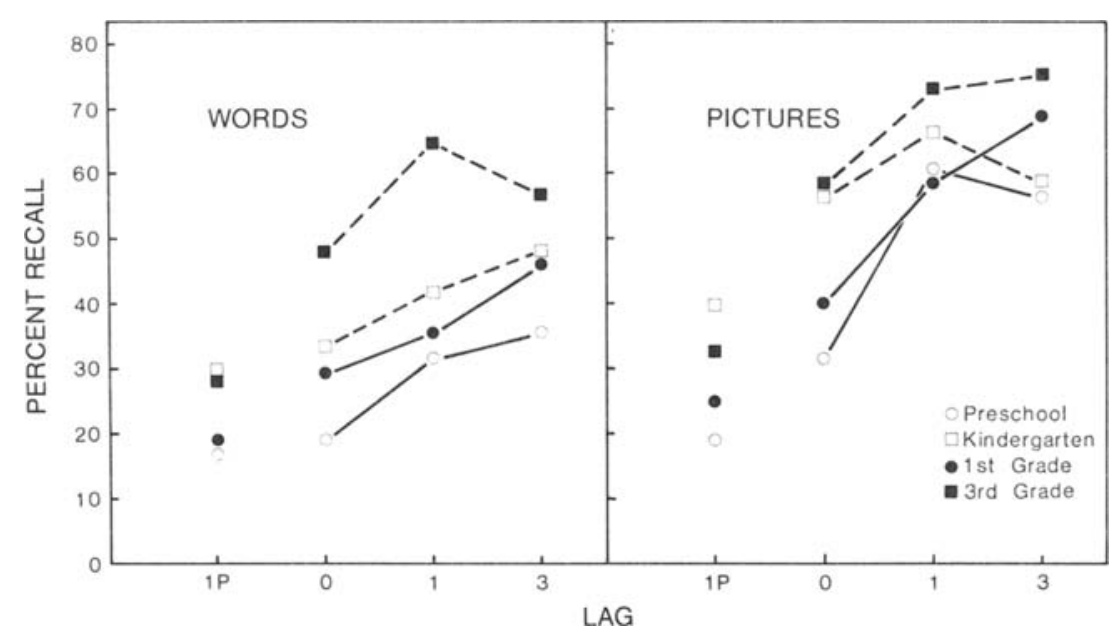

Figure 1. Percent recall as a function of lag, age group, and material in Experiment 1.

set at .01 . The first question of interest was whether items repeated at Lag 0 were recalled better than $1 P$ items. The results of a 4 (age) $\times 2$ (lag) $\times 2$ (material) analysis of variance (ANOVA) showed that recall of Lag 0 items (mean $=.79)$ was better than recall of $1 \mathrm{P}$ items $($ mean $=$ $.52)[F(1,92)=13.95, M S e=.51]$. There were also significant main effects of age $[F(3,92)=5.36, M S e=.64]$ and material $[F(1,92)=11.54, M S e=.29]$. There were no significant interactions (all $F \mathrm{~s} \leq 1.00$ ).

$A$ second question was whether recall increased with spacing. Thus, a 4 (age) $\times 3$ (lag) $\times 2$ (material) ANOVA was carried out. The results showed that all three main effects were significant. There were no significant interactions (all $F_{\mathrm{s}}<1.00$ ).

Recall increased with lag. Mean recall for Lags 0, 1, and 3 was $.79,1.08$, and 1.11 , respectively $[F(2,184)=$ $12.49, M S e=.49]$. Further comparisons showed that the increase from Lag 0 to $\mathrm{Lag} 1$ was reliable $[F(1,92)=$ $17.62, M S e=.46]$ but that the small increase from Lag 1 to Lag 3 was not $[F(1,92)=.23, M S e=.41]$. Recall increased with age. Mean recall for preschool, kindergarten, first-grade, and third-grade children was .78, 1.01, .92 , and 1.25 , respectively $[F(3,92)=10.93$, $M S e=.52]$. Further comparisons showed that thirdgrade children recalled more than either first-graders $[F(1,46)=17.36, M S e=.44]$ or kindergarteners $[F(1,46)=7.39, M S e=.54]$, that first-graders and kindergarteners did not differ significantly from each other $[F(1,46)=1.04, M S e=.56]$, and that both first-graders and kindergarteners recalled more than did the preschoolers $[F(1,70)=6.38, M S e=.55]$. Finally, pictures (mean $=1.17$ ) were recalled better than words $($ mean $=.81)[F(1,92)=35.18, M S e=.52]$.

\section{Discussion}

The data from Experiment 1 did not confirm Toppino and DiGeorge's (1984) findings. Contrary to their results, we found that preschoolers, as well as older children, benefited from repetitions that were spaced rather than massed.

Our results suggest that the beneficial effects of spacing increase rapidly between Lag 0 and Lag 1 and much less so beyond this point. Furthermore, the spacing effect was obtained with each of two types of material, a finding that suggests that, whatever the underlying mechanism, it is not differentially effective with words and pictures.

The results indicated that items repeated at Lag 0 were recalled better than $1 \mathrm{P}$ items. At Lag 0 there actually was a 1.1-sec blank interval for slide changes between successive repetitions. Thus, the data indicate that a spacing of only $1.1 \mathrm{sec}$ can produce a beneficial effect. In this context, it should be noted that Hintzman, Summers, and Block (1975) also found, with adult subjects, that a blank interval between successive presentations of as little as $.8 \mathrm{sec}$ facilitated subsequent recall. The data of Experiment 1 also showed that retention was further facilitated at Lag 1, corresponding to a spacing of $5 \mathrm{sec}$ between repetitions, but not at Lag 3 . These results suggest that, with this population of subjects, increased spacing is most beneficial in the 0-5-sec range and that precise control of very brief spacings is necessary to chart the spacing effect.

Experiment 2 was designed to examine the spacing effect over such brief intervals. Normally, the interval between repeated items involves other items in order to prevent or minimize rehearsal. It would be difficult, however, to use this procedure to examine the effect associated with spacings as brief as $1 \mathrm{sec}$. Fortunately, the use of intervening items to prevent rehearsal does not appear to be necessary with young children. Although very young children can use nonverbal behaviors (e.g., pointing, touching, looking) to improve memory (Acredolo, Pick, \& Olsen, 1975; Ryan, Hegion, \& Flavell, 1970; Siegel, Allik, \& Herman, 1976; Wellman, Ritter, \& Flavell, 1975; Yussen, 1974), children younger than approximately 8 years 
of age seem unable to use verbal rehearsal spontaneously as an effective strategy to enhance memory (Appel et al., 1972; Flavell et al., 1966; Hagen \& Kingsley, 1968; Naus \& Ornstein, 1983; Ornstein, Medin, Stone, \& Naus, 1985; Ornstein \& Naus, 1978). If young children do not typically engage in effective verbal rehearsal, then the experimental manipulation of using intervening items to prevent rehearsal during successive presentations is unnecessary. Thus, in Experiment 2 the intervals between presentations were left blank.

\section{EXPERIMENT 2}

\section{Method}

Subjects. The subjects were 96 children, 24 each from four age groups: preschool (mean $=4.3$ years), kindergarten (mean age $=$ 5.5 years), first grade (mean age $=6.5$ years), and third grade (mean age $=8.6$ years). Approximately half the children were male and half were female, and all were from a local preschool and elementary school. (These schools were different from those of Experiment 1 , but were considered equivalent in terms of socioeconomic status.)

Design. The design was a $4 \times 2 \times 4$ factorial involving the four age groups just described, two types of material (words and pictures), and four levels of spacing $(0,1.1,2.5$, and $5 \mathrm{sec})$. Age was a between-subjects variable, and material and spacing were withinsubject variables.

Materials and Apparatus. The stimulus materials and apparatus were the same as those used in Experiment 1. A computer program was developed to control the recording of electronic cue pulses on one track of the cassette tape for the various spacings required. Thus, very precise control over the interstimulus interval between repeated items and slide presentations was obtained. The corresponding audio presentation (female voice) of each item was recorded on the other track. The sequence of events in each of the four spacing conditions is summarized in Figure 2. For the $0-\mathrm{sec}$ spacing condition, the slide was exposed without interruption for a total of $8.9 \mathrm{sec}$, conceptualized as two visual presentations of $4.45 \mathrm{sec}$ each, with a true 0 -sec interval between them. The visual presentation at 0 -sec spacing was accompanied by two repeated audio presentations of the picture shown (e.g., "dog"), one coinciding with slide onset and the other occurring at $4.45 \mathrm{sec}$, that is, in the middle of the visual exposure interval. Strictly speaking, therefore, true 0 -sec spacing refers to the visual component of the stimulus presentation and not the audio one.

For the 1.1-sec spacing condition, the first presentation of the slide $(\mathrm{P} 1)$ had a duration of $3.9 \mathrm{sec}$. This was followed by a blank interval of $1.1 \mathrm{sec}$ and then the second presentation of the slide (P2), which was also $3.9 \mathrm{sec}$ in duration. Voice onset was coordinated with the onset of each slide. Total time from onset of P1 to the offset of P2 was $8.9 \mathrm{sec}$, the same total time lapse between slide onset and offset was used in the 0 -sec spacing condition. Notice that the 1.1-sec spacing condition corresponds to the Lag 0 condition in Experiment 1. That is, both involve the situation in which two immediate successive slide presentations are separated by the time needed for the projector to change slides, that is, $1.1 \mathrm{sec}$ in the present case.

For the spacing conditions of 2.5 and $5 \mathrm{sec}$, the blank times between P1 slide offset and P2 slide onset, created by the use of blank slides, were 2.5 and $5 \mathrm{sec}$, respectively. Audio presentation accompanied onset of each slide.

For each type of stimulus material (words or pictures), 16 lists were constructed, each of 17 positions. The first 2 and last 3 positions were reserved for primacy and recency buffers, respectively. Eight of the 12 middle positions were taken by four items presented

\section{SPACING}

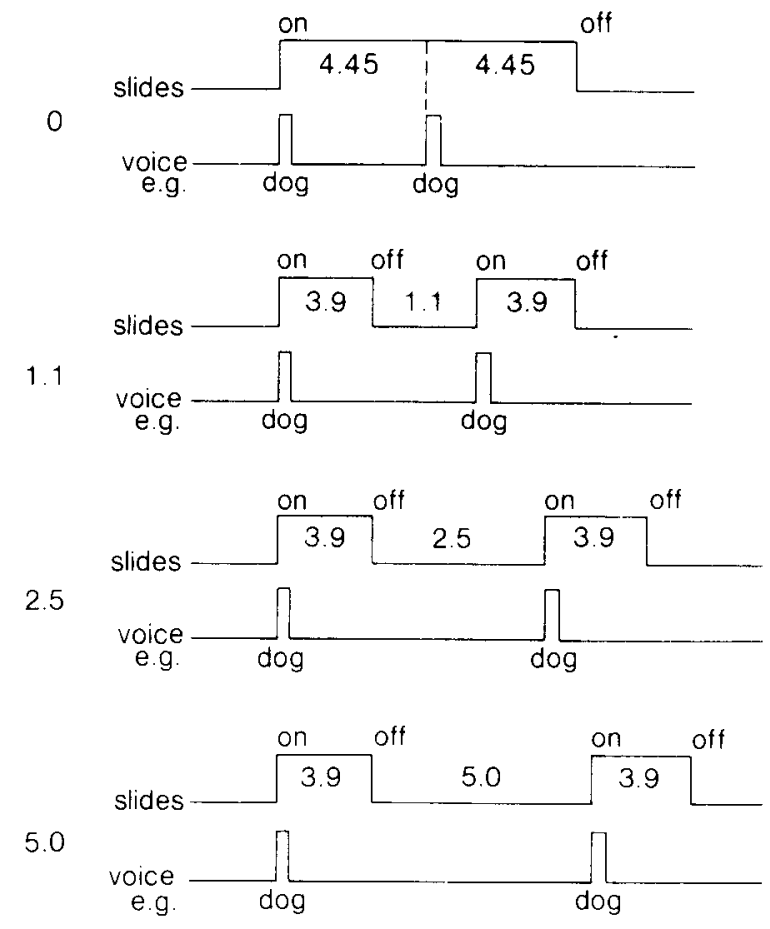

Figure 2. Sequence of visual (slides) and auditory (voice) presentation events in Experiment 2.

twice, one each at spacings of $0,1.1,2.5$, and 5 sec. Two positions were taken by once-presented items randomly selected from the filler items used in Experiment 1, and 2 by the blank slides used for the 2.5- and 5-sec spacing conditions. In order that the same set of items serve in all four spacing conditions and that each item be equally represented in all positions in the lists, a Greco-Latin square principle was used to counterbalance items and conditions. Each subject received 2 word lists (W) and 2 picture lists (P). For counterbalancing purposes, eight separate sequences of word and picture lists were constructed. In every age group, 3 subjects each received one of the eight sequences. Half received a W, P, W, P order, and half received a P, W, P, W order.

Procedure. The procedure was identical to that of Experiment 1. The children were tested individually. After listening to the standard set of instructions, they were given a practice list and then the four experimental lists. A 2-min oral free recall followed each list presentation.

\section{Results}

As in Experiment 1, each subject obtained a score of 0,1 , or 2 for each type of material (words and pictures); the score depended on whether he/she recalled neither, one, or both of the target items in each of the four spacing conditions. The main results are summarized in Figure 3.

In order to examine the spacing function, we performed a 4 (age) $\times 4$ (spacing) $\times 2$ (material) ANOVA. Mean recall for spacings of $0,1.1,2.5$, and $5 \sec$ was $.67, .89$, .75 , and 1.07 , respectively $[F(3,276)=10.81, M S e=$ .45]. Further comparisons showed that recall improved from the 0 - to the $1.1-\mathrm{sec}$ spacing $[F(1,92)=10.22$, $M S \mathrm{e}=.41]$ and from the 2.5 - to the 5-sec spacing 


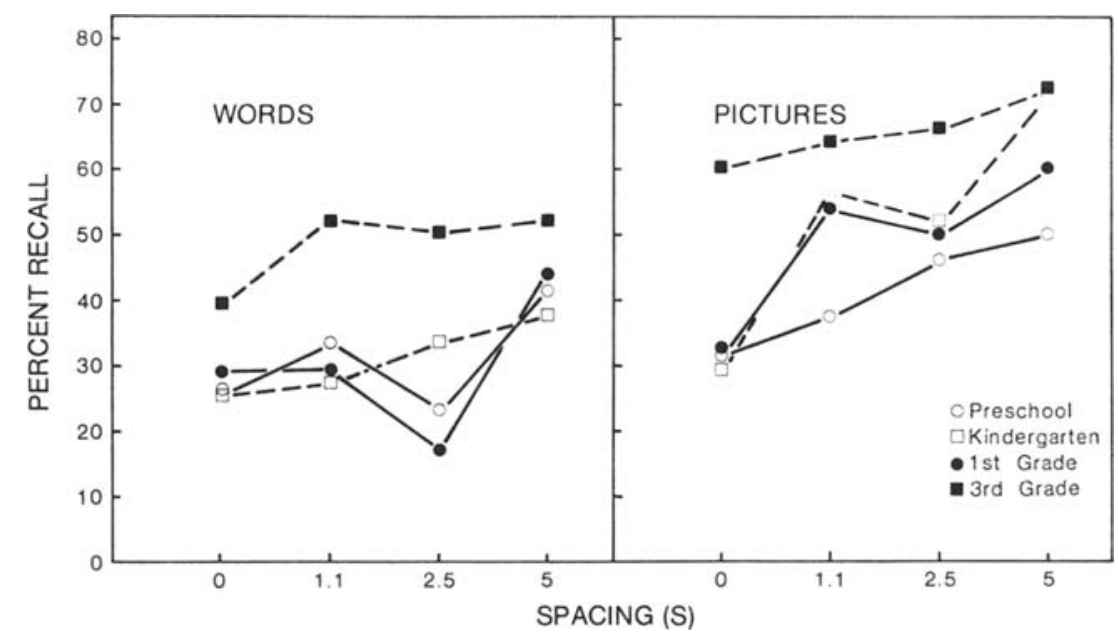

Figure 3. Percent recall as a function of spacing, age group, and material in Experiment 2.

$[F(1,92)=10.05$, MSe $=.46]$, but the difference between the 1.1- and 2.5-sec spacings was not reliable $[F(1,92)=.36, M S e=.46]$.

Recall increased with age: means $=.72, .83, .79$, and 1.14 for preschool, kindergarten, first-grade, and thirdgrade children, respectively $[F(3,92)=13.62, M S e=$ .48]. Other analyses showed that preschoolers, kindergarteners, and first-graders did not differ significantly in their levels of recall $[F(2,69)=1.35, M S e=.44]$. Thirdgrade children $($ mean $=1.14$ ), however, recalled significantly more than the other three age groups combined $($ mean $=.78)[F(1,94)=38.23, M S \mathrm{e}=.48]$.

Finally, pictures (mean $=1.04)$ were recalled better than words (mean $=.70)[F(1,92)=40.94, M S e=.54]$. There were no significant interactions (all $F \mathrm{~s}<1.50$ ).

\section{Discussion}

The main results of Experiment 2 were that the spacing effect was obtained with blank spacings between presentations and that the effect occurred at all age levels tested. The results also showed that the benefits of spacing increase with spacings of up to $5 \mathrm{sec}$ and that spacings (between visual presentations) as short as $1.1 \mathrm{sec}$ can improve recall over recall found with a true 0 -sec spacing.

\section{GENERAL DISCUSSION}

Both experiments showed that, contrary to Toppino and DiGeorge's (1984) results, children as young as 4 years of age can benefit from spaced repetitions. Moreover, a similar spacing function was found across all groups, ranging from approximately 4 to 9 years of age. These results are consistent with those of other researchers who have demonstrated the spacing effect with children (e.g., Toppino \& DeMesquita, 1984; Wilson, 1976). Generally, our findings, to the extent they show that the spacing effect does not emerge with development, support theories of the spacing effect that rely on the operation of involun- tary (automatic) mechanisms. In the remainder of this section, we dicuss how these data specifically relate to different theories.

Hintzman (1976) classified theories of the spacing effect under two general headings: deficient processing and encoding variability theories. Deficient processing theories assume that when two presentations (P1 and $\mathrm{P} 2$ ) are massed, either the first or the second may not be fully processed. With increased spacing, however, the probability of further processing of either one or both presentations increases and better recall typically results. Four deficient processing theories have been proposed, two of which can be classified as voluntary (rehearsal or attention) and two as involuntary (consolidation or habituation).

Rundus's (1971) rehearsal hypothesis assumes that subjects voluntarily rehearse $P 1$ information. This hypothesis seems to be least compatible with the present results. Children in the age range tested in both experiments do not typically engage in spontaneous verbal rehearsal (Appel et al., 1972; Flavell et al., 1966; Hagen \& Kingsley, 1968; Naus \& Ornstein, 1983; Ornstein et al., 1985; Ornstein \& Naus, 1978). Yet, a spacing effect appeared in both experiments.

A second deficient processing explanation of the spacing effect, also based on voluntary activity, is the attention hypothesis (Hintzman, 1974, 1976; Underwood, 1969,1970 ). According to this view, subjects do not attend to and do not fully process the second presentation of a massed item, but devote more attention to $\mathrm{P} 2$ as spacing increases. A major problem with this hypothesis is that the term attention has not been clearly operationally defined. For example, attention may be conceptualized as a precursor of or a necessary precondition for cognitive processing, such as a encoding, associating, or rehearsing, to take place. In this sense, attention is a corollary to perceiving. However, some researchers (e.g., Shaughnessy, Zimmerman, \& Underwood, 1974; Zimmerman, 1975) have used the term attention interchange- 
ably with cognitive processing activities such as encoding, elaborating, or rehearsal, and do not define attention as a separate mechanism from these activities. Therefore, depending on how one conceptualizes attention, the present results may or may not support this form of the attention hypothesis.

Habituation and consolidation are the two involuntary deficient processing theories that have been proposed. According to the habituation hypothesis (Hintzman, 1974), the mechanism responsible for encoding P1 is engaged for some time following P1 (i.e., it habituates) and will not respond to $\mathrm{P} 2$ until sufficient time has passed for recovery of that process to take place. The consolidation hypothesis (Landauer, 1969, 1974) suggests that deficient processing results because, when $\mathrm{P} 1$ and $\mathrm{P} 2$ are contiguous, the amount of consolidation produced by both items together will be less than if $P 2$ is delayed until consolidation of $\mathrm{P} 1$ is complete.

The major problem with both hypotheses is that the time course of consolidation or recovery from habituation is not known. Hintzman et al. (1975) concluded that habituation would have to asymptote in less than $2.2 \mathrm{sec}$ for the habituation hypothesis to be supported. If this were true, there should have been no difference between the 2.5- and the 5-sec spacing conditions in Experiment 2, contrary to the actual findings.

The time course of consolidation has been estimated to range from $15 \mathrm{sec}$ to more than $1 \mathrm{~h}$ (Baddeley, 1976). The fact that the spacing effect was obtained with very short spacings in the present study would be inconsistent with such estimates.

Next, consider encoding variability theories (e.g., Glenberg, 1979; Martin, 1972; McFarland, Rhodes, \& Frey, 1979; Melton, 1970; Wells \& Kirsner, 1974). The major thrust of encoding variability theories is that, as spacing increases, the two presentations are associated with increasingly different (externally and/or internally generated) contexts. A common version assumes that the probability that repeated items are grouped with different list items increases with spacing. The data of Experiment 1 are consistent with this hypothesis. Those of Experiment 2, however, are less so. In Experiment 2, all four spacing conditions were equivalent in the probability that repeated items would be grouped with other list items, since repetitions were separated by blank intervals. Thus, according to the grouping hypothesis, there should have been no increase in retention as a function of spacing, because increased spacing did not involve increased probability that the repetitions would be grouped with different items. The opposite, however, occurred.

An ad hoc encoding variability interpretation of the Experiment 2 data would have to assume that the context changed as the length of the blank interval increased. In general, encoding variability has not fared well (e.g., Bird, Nicholson, \& Ringer, 1978; Maskarinec \& Thompson, 1976; Postman \& Knecht, 1983; Ross \& Landauer, 1978; Toppino \& Gracen, 1985; Young \& Bellezza, 1982).
A final class of theory to be considered here is derived from the levels-of-processing point of view (Craik \& Lockhart, 1972). Various formulations that share this theme have been proposed (e.g., Jacoby, 1978; Magliero, 1983; Rose, 1980, 1984; Rowe \& Rose, 1977). The basic notion is that when items are massed, the subject need not process the second presentation to the same extent as the first because it is easily contacted in recent episodic memory. As spacing increases between $\mathrm{P} 1$ and $\mathrm{P} 2$, more effort than mere scanning of episodic memory must be expended, and the subject must reconstruct or repeat the processing used at $\mathrm{Pl}$.

The reconstruction or effort hypotheses are also consistent with views that retrieval operations strengthen the memory trace (Runquist, 1983, 1986). Runquist reported that the slope of the forgetting curve was reduced more for items receiving an initial test than for those not receiving an initial test. In Runquist's procedure, the initial recall test occurred $2 \mathrm{~min}$ after subjects studied a list of 24 items. Modigliani (1976), on the other hand, found that successful recalls strengthened the recalled items after distracting intervals of just a few seconds and that the strengthening effect increased with the length of that interval, reaching asymptote in a matter of 5-10 sec.

Thus, considerable research points to successful retrieval operations as possible key mechanisms that strengthen the memory trace of retrieved items. We believe that this may be an important factor in understanding the spacing effect. In general terms, the assumption would be that the second of two presentations is effective to the extent that it engenders a retrieval of the first and that the effort involved in a successful retrieval operation increases with spacing.

In conclusion, the present data, obtained with young children, generally favor interpretations of the spacing effect that stress the operation of involuntary (automatic) mechanisms. These may include habituation, consolidation, encoding variability, or retrieval operation mechanisms. Although the present data do not allow a clear discrimination among these, we believe that the developmental approach taken here, and in few other studies (e.g., Cornell, 1980; Toppino \& DeMesquita, 1984; Toppino \& DiGeorge, 1984; Wilson, 1976), is a useful and innovative way to investigate the robust, but theoretically elusive, spacing effect.

\section{REFERENCES}

Acredolo, L. P., Pick, H. L., JR., Olsen, M. G. (1975). Environmental differentiation and familiarity as determinants of children's memory for spatial location. Developmental Psychology, 11, 495-501.

Appel, L. F., CoOper, R. G., McCarRell, N., Sims-Knight, J., YusSEN, S. R., \& FlAVELL, J. H. (1972). The development of the distinction between perceiving and memorizing. Child Development, 43, 1365-1381

BADDELEY, A. D. (1976). The psychology of memory. New York: Basic Books.

Bird, C. P., Nicholson, A. J., \& Ringer, S. (1978). Resistance of the spacing effect to variations in encoding. American Journal of Psychology, 91, 713-721. 
BLoOM, K. F., \& SHUELL, T. J. (1981). Effects of massed and distributed practice on the learning and retention of second-language vocabulary. Journal of Educational Research, 74, 245-248.

CoRnEll, E. H. (1980). Distributed study facilitates infants' delayed recognition memory. Memory \& Cognition, 8, 539-542.

Craik, F. I. M., \& LockharT, R. S. (1972). Levels of processing: A framework for memory research. Journal of Verbal Learning \& Ver bal Behavior, 11, 671-686.

Crowder, R. G. (1976). Principles of learning and memory. Hillsdale, NJ: Erlbaum.

Flavell, J. H., Beach, D. R., \& Chinsky, J. M. (1966). Spontaneous verbal rehearsal in a memory task as a function of age. Child Development, 37, 283-299.

Glenberg, A. M. (1979). Component-levels theory of the effects of spacing of repetitions on recall and recognition. Memory \& Cognition, 7, 95-112.

HAGEN, J. W., \& KingsLey, P. R. (1968). Labeling effects in shortterm memory. Child Development, 39, 113-121.

Hintzman, D. L. (1974). Theoretical implications of the spacing effect. In R. L. Solso (Ed.), Theories in cognitive psychology: The Loyola symposium. Potomac, MD: Erlbaum.

HintzMAN, D. L. (1976). Repetition and memory. In G. H. Bower (Ed.), The psychology of learning and motivation (Vol. 10). New York: Academic Press.

Hintzman, D. L., \& Rogers, M. K. (1973). Spacing effects in picture memory. Memory \& Cognition, 1, 430-434.

Hintzman, D. L., Summers, J. J., \& Block, R. A. (1975). What causes the spacing effect? Some effects of repetition, duration, and spacing on memory for pictures. Memory \& Cognition, 3, 287-294.

JACOBY, L. L. (1978). On interpreting the effects of repetition: Solving a problem versus remembering a solution. Journal of Verbal Leam ing \& Verbal Behavior, 17, 649-667.

KINTsCH, W. (1966). Recognition learning as a function of the length of the retention interval and changes in retention interval. Journal of Mathematical Psychology, 3, 412-433.

LANDAuer, T. K. (1969). Reinforcement as consolidation. Psychological Review, 76, 82-96.

LANDAUER, T. K. (1974). Consolidation in human memory: Retrograde amnesia effects of confusable items in paired-associate learning. Journal of Verbal Learning \& Verbal Behavior, 13, 45-53.

LANDaUER, T.K., \& Ross, B. H. (1977). Can simple instructions to use spaced practice improve ability to remember a fact? An experimental test using telephone numbers. Bulletin of the Psychonomic Society, 10, 215-218.

LofTus, G. R. (1982). Picture memory methodology. In C. R. Puff (Ed.), Handbook of research methods in human memory and cognition. New York: Academic Press.

LofTUs, G. R., KallmaN, H. J. (1979). Encoding and use of detail information in picture recognition. Journal of Experimental Psychology: Human Learning \& Memory, 5, 197-211.

Magliero, A. (1983). Pupil dilations following pairs of identical and related to-be-remembered words. Memory \& Cognition, 11, 609-615.

MarTiN, E. (1972). Stimulus encoding in learning and transfer. In A.W. Melton \& E. Martin (Eds.), Coding processes in human memory. Washington, DC: Winston.

Maskarinec, A. S., \& Thompson, C. P. (1976). The within-list distributed practice effect: Tests of the varied context and varied encoding hypothesis. Memory \& Cognition, 4, 741-746.

McFarland, C. E., JR., Rhodes, D. D., \& FEY, T. J. (1979). Semantic feature variability and the spacing effect. Joumal of Verbal Leaming \& Verbal Behavior, 18, 163-172.

Melton, A. W. (1967). Repetition and retrieval from memory. Science, 158, 532 .

Melton, A. W. (1970). The situation with respect to the spacing of repetitions and memory. Journal of Verbal Learning \& Verbal Behavior, 9, 596-606.

ModiguaNi, V. (1976). Effects on a later recall by delaying initial recall. Journal of Experimental Psychology: Human Learning \& Memory, 2, 609-622.
Naus, M. J., \& ORnStein, P. A. (1983). Development of memory strategies: Analysis, questions, and issues. In M. T. H. Chi (Ed.), Trends in memory development research: Contributions to human development (Vol. 9, pp. 1-30). Basel: Karger.

Ornstein, P. A., Medin, R. G., Stone, B. P., \& Naus, M. J. (1985). Retrieving for rehearsal: An analysis of active rehearsal in children's memory. Developmental Psychology, 21, 633-641.

Ornstein, P. A., \& Naus, M. J. (1978). Rehearsal processes in children's memory. In P. A. Ornstein (Ed.), Memory development in children. Hillsdale, NJ: Erlbaum.

Postman, L., \& KNecht, K. (1983). Encoding variability and retention. Journal of Verbal Learning \& Verbal Behavior, 22, 133-152.

RosE, R. J. (1980). Encoding variability, levels of processing, and the effects of spacing of repetitions upon judgments of frequency. Memory \& Cognition, 8, 84-93.

Rose, R. J. (1984). Processing time for repetitions and the spacing effect. Canadian Joumal of Psychology, 83, 537-550.

Ross, B. H., \& Landauer, T. K. (1978). Memory for at least one of two items: Test and failure of several theories of spacing effects. Journal of Verbal Learning \& Verbal Behavior, 17, 669-680.

Rowe, E. J., \& Rose, R. J. (1977). Effects of orienting task, spacing of repetitions, and list context on judgments of frequency. Memory \& Cognition, 5, 505-512.

Rundus, D. (1971). Analysis of rehearsal processes in free recall. Journal of Experimental Psychology, 89, 63-77.

RUNQUIST, W. (1983). Some effects of remembering on forgetting. Memory \& Cognition, 11, 641-650.

RUNQuist, W. (1986). The effect of testing on the forgetting of related and unrelated associates. Canadian Journal of Pschology, 40, 65-76.

Ryan, S. M., Hegion, A. G., Flavell, J. H. (1970). Nonverbal mnemonic mediation in preschool children. Child Development, 41, 539-550.

SchwarTz, M. (1975). The effect of constant vs. varied encoding and massed vs. distributed presentations on recall of paired associates. Memory \& Cognition, 3, 390-394.

Shaughnessy, J. J. (1977). Long-term retention and the spacing effect in free recall and frequency judgments. American Journal of Psychology, 90, 587-598.

Shaughnessy, J. J., Zimmerman, J., \& Underwood, B. J. (1974). The spacing effect in the learning of word pairs and the components of word pairs. Memory \& Cognition, 2, 742-748.

Siegel, A. W., Allik, J. P., \& Herman, J. F. (1976). The primacy effect in young children: Verbal fact or spatial artifact? Child Development, 47, 242-247.

SNODGRASS, J., \& VANDERWART, M. (1980). A standardized set of 260 pictures: Norms for name agreement, image agreement, familiarity and visual complexity. Journal of Experimental Psychology: Human Learning \& Memory, 6, 174-215.

TopPINo, T. C., \& DEMEsquita, M. (1984). Effects of spacing repetitions on children's memory. Joumal of Experimental Child Psychology, 37, 637-648.

Toppino, T. C., \& DiGeorge, W. (1984). The spacing effect in free recall emerges with development. Memory \& Cognition, 12, 118-122.

Toppino, T. C., \& Gracen, T. F. (1985). The lag effect and differential organization theory: Nine failures to replicate. Journal of Experimental Psychology: Leaming, Memory, \& Cognition, 11, 185-191. UNDERWOOD, B. J. (1969). Some correlates of item repetitions in free recall learning. Joumal of Verbal Learning \& Verbal Behavior, 8 , 83-94.

UNDERWOOD, B. J. (1970). A breakdown of the total-time law in free recall learning. Journal of Verbal Learning \& Verbal Behavior, 9, 573-580.

Wellman, H. M., Rutter, K., \& Flavell, J. H. (1975). Deliberate memory behavior in the delayed reactions of very young children. Developmental Psychology, 11, 780-787.

WELLS, E., \& KIRSNER, K. (1974). Repetition between and within modalities in free recall. Bulletin of the Psychonomic Society, 2, 395-397.

WEPMAN, J. M., HAss, W. (1969). A spoken word count (children ages 5, 6, and 7). Chicago, L: Language Research Associates. 
WhIrten, W. B., II, \& BJoRK, R. A. (1977). Learning from tests: Effects of spacing. Journal of Verbal Learning \& Verbal Behavior, 16 465-478.

WILson, W. P. (1976). Developmental changes in the lag effect: An encoding hypothesis for repeated word recall. Joumal of Experimental Child Psychology, 22, 113-122.

Young, D. R., \& BELlezZA, F. S. (1982). Encoding variability, memory organization, and the repetition effect. Joumal of Experimental Psychology: Learning, Memory, \& Cognition, 8, 545-559.
YusSeN, S. R. (1974). Determinants of visual attention and recall in observational learning by preschoolers and second graders. Developmental Psychology, 10, 93-100.

Zimmerman, J. (1975). Free recall after self-paced study: A test of the attention explanation of the spacing effect. American Journal of Psychology, 88, 277-291.

(Manuscript received June 25, 1986; revision accepted for publication November 10, 1986.) 